\title{
Exploitation in Human Trafficking and Smuggling
}

\author{
Paolo Campana \\ Institute of Criminology \\ University of Cambridge \\ Federico Varese \\ Extra-legal Governance Institute \\ Department of Sociology \\ University of Oxford
}

Version submitted for publication in the European Journal on Criminal Policy and Research Accepted on 13.07.2015

Corresponding Author's contact details:

Institute of Criminology, University of Cambridge

Sidgwick Avenue, Cambridge CB3 9DA

United Kingdom

Telephone: +44 (0)1223 767375

Email: pc524@cam.ac.uk 


\section{Exploitation in Human Trafficking and Smuggling}

Abstract: This article explores the mechanisms that underpin human smuggling and trafficking. It argues for the continued analytical relevance of the distinction between "trafficking" and "smuggling", as posited by the 2000 UN Protocols. While this distinction has come under sustained criticism from several authors over the last 15 years, it nonetheless continues to capture the essential features of two distinct phenomena (control over a human being vs. illegal entry into a country), and acknowledges the role of agency in smuggling. The paper goes on to discuss three different scenarios that may emerge as a result of the interplay between smugglers and smuggled persons, and it specifies the role of exploitation in each scenario. In addition, the paper offers empirical evidence of the key building blocks of smuggling - namely the search for reliable information and the reaching of an agreement in regard to the service offered - and of how smuggling can turn into trafficking. This work concludes by drawing out the relevant policy implications.

Key words: Human trafficking. Migrant smuggling. Exploitation. Informal agreements. 


\section{Human trafficking vs. smuggling: The debate around a dichotomy}

In 2000, the United Nations adopted two distinct Protocols on trafficking in human beings and the smuggling of migrants (Gozdziak and Collett 2005). The Protocols, building on the Europol Convention (1995), define trafficking as "control over another person for the purpose of exploitation” (UN 2000a: 2), including forms of sexual exploitation, forced labour, slavery, servitude and the removal of organs. Smuggling, on the other hand, is defined as the procurement of an illegal entry into a country (UN2000b). In stark terms then, the Protocols posit that trafficking and smuggling are two distinct phenomena. ${ }^{1}$ The definitions outlined in the UN Protocols have shaped the debate about trafficking and smuggling ever since (see, for example, Aronowitz 2001; Savona et al. 2002; Kleemans and van de Bunt 2003; Savona et al. 2003; Gozdziak and Collett 2005; Savona and Stefanizzi 2007; Danailova-Trinov and Laczko 2010; Wheaton et al. 2010; Triandafyllidou and Maroukis 2012; Hoyle et al. 2011; Kleemans 2011; Chin and Finckenauer 2012; Caneppele and Mancuso 2013; Mancuso 2013; Campana 2015). ${ }^{2}$ However, this dichotomy has come under increasing criticism.

Salt and Stein (1997) outlined an alternative model premised on a rather broad definition of trafficking, which they defined as "an intermediary part of the global migration business facilitating movement of people between origin and destination country" (1997: 467). Trafficking, they write, "may be regarded as the practice of trading 'illegally' in the movement of people" (p. 471), and it is defined as a business in which the commodities exchanged involve "the trading and systematic movement of people" (1997: 471). Whether a migrant has some agency or the freedom to make a voluntary choice at any stage of the movement is not regarded as relevant. In fact, the authors appear rather ambivalent in this respect. They maintain that "there is increasing evidence that migrants are turning to the service of traffickers" (p. 469), thus implying some level of agency on the migrants' side. However, Salt and Stein do not see the need for a distinction between trafficking 
and smuggling based on whether a migrant is coerced into the movement against their will. The terms "smuggling" and "trafficking" are thus used interchangeably, and the issue of agency elided altogether. In a later article, Salt (2000: 33) maintains that "trafficking and more voluntary forms of undocumented migrations are best thought of as a continuum", since it is often difficult to establish whether elements of deception and/or coercion have come into play, and he suggests that human rights abuses may also occur in a smuggling operation. Moreover, trafficking may involve elements of smuggling, "particularly when it uses the same routes, forged documentation and organizational networks as the smugglers" (Salt 2000: 34). In addition, people who have been smuggled may not know the "degree and nature of exploitation that awaits them": for these reasons, it is claimed that the entire continuum is best termed trafficking (p. 34). Other authors have used the two terms interchangeably, for example Shelley (2010). Oddly, Shelley interprets human trafficking and smuggling as forms of organised crime generated by globalisation (2010: 2).

Some scholars have proposed definitions of trafficking that conflate a variety of different phenomena. In her influential article on the so-called "Natasha trade", i.e. the trafficking of women from Eastern Europe for the purpose of sexual exploitation, Hughes (2000: 627) defines trafficking as "any practice that involves moving people within and across local and national borders for the purpose of sexual exploitation." She adds that trafficking may be achieved not only by force, coercion, manipulation, deception and abuse of authority, as in the UN definition, but also as a result of "family pressure, past and present family and community violence, economic deprivation, or other conditions of inequality for women and children" (2000: 628; along similar lines, see Williams 2012). This definition both limits and stretches the concept of trafficking. On the one hand, it excludes trafficking for purposes other than sexual exploitation and conflates it with prostitution. On the other hand, it includes any form of economic or emotional pressure, while excluding the possibility that agency plays any role. As inequality and deprivation may be relative 
to various societal models of consumption or behaviour, one could be justified in including advertising as a form of emotional pressure (for additional critiques, see Zhang 2009; Chin and Finckenauer 2012: 266-270; Agustin 2005, and Spencer and Broad 2012).

Recently, there have been several attempts to shift the focus from trafficking (strictly conceived) to a broader "human rights perspective". For instance, the EU Expert Group on Trafficking (2004) maintained that "there is no reason to distinguish between forced labour and services involving ‘illegal migrants', 'smuggled persons' or 'victims of trafficking'” (EU 2004: 53). Gallagher (2009: 792) argues against “the strange legal fiction [...] that 'trafficking' and 'migrant smuggling' are two completely different crimes involving helpless, virtuous victims on the one side and foolish or greedy adventurers, complicit in their own misfortune, on the other." She advocates a very broad interpretation of trafficking that includes a range of different phenomena, such as traditional debt bondage systems, sale of children into prostitution, 'new' forms of debt bondage in the sex industry and various forms of labour exploitation (e.g. in the charcoal industry in Brazil, in the construction sector in Russia, on fishing boats in Thailand, on cocoa farms in Cote d'Ivoire as well as among domestic helpers working in Western countries: pp. 815-816). More generally, Gallagher (2009: 817) conceives of trafficking as an instance where "exploited individuals" are at the same time "victims of a serious crime as well as a victim of human rights violation". Finally, she argues that a human rights-based approach would put sovereign states under closer scrutiny while creating more opportunities for victims to obtain protection, for instance by broadening the boundaries of international refugee law to include instances of "trafficking as persecution, trafficking as a form of gender-based persecution, retrafficking and reprisal against victims and their families as persecution, trafficking-related trauma, discrimination and ostracism as persecution" (Gallagher 2009: 845). 
Other authors have favoured the notion of modern slavery over trafficking. In his book Disposable People, Bales (2012: 6) defines modern slavery as "the total control of one person by another for the purpose of economic exploitation”. Bales (2012: 19-20) identifies some key forms of modern slavery, namely chattel slavery (when a "person is captured, born, or sold into permanent servitude"), debt bondage (when a "person pledges him- or herself against a loan of money" with the possibility of passing on the debt to offspring), and contract slavery (when workers are "threatened by violence, lacking any freedom of movement, and paid nothing"). His notion also encompasses 'war slavery', namely the "widespread capture and enslavement of civilians by the government and the army” (p. 21). In the same vein, Kara (2009:5) challenges the value of the UN definition of trafficking, which is considered a "linguistic attenuation [that] scrambles global attention and blunts abolitionist policies". Instead, he advocates the adoption of a notion of "modern slavery' defined as "the process of coercing labor or other services from a captive individual, through any means, including exploitation of bodies or body parts" (Kara 2009: 5).

Hathaway (2008:4-5) also criticises the UN Protocol for being too narrow in its definition of trafficking, with the consequence of "hiving off a relatively minor part of the slavery issue - no more than three per cent of modern slaves meet the definition of a 'trafficked person' under the Trafficking Protocol". In his view, anti-trafficking campaigns privilege "a small subset of persons subject to contemporary forms of slavery, with consequent marginalization of the majority of the world's slaves" (p. 6). Therefore, he argues for a much broader definition of the phenomenon: for instance, one that equates exploitation with trafficking (pp. 10 and 49). Hathaway also suggests that the UN Trafficking Protocol may have created negative "human rights externalities" by driving states toward increased criminalisation of non-abusive smuggling operations and the heightening of border controls. This drive, Hathaway (2008: 13) claims, "may endanger would-be migrants, in particular by converting simple smuggling into highly risky trafficking situations”. 
The 2000 UN Protocols have, then, been criticised in a number of different ways. Critics have proposed merging trafficking and smuggling (Salt and Stein 1997; Salt 2000), as well as identifying trafficking with prostitution (Hughes 2000) and modern slavery (Bales 2012; Hathaway 2008). Others have advocated a broader "human rights approach" (EU 2004; Gallagher 2009). All such attempts call into question the meaningfulness of the distinction between trafficking and smuggling. This paper, on the other hand, defends the importance of drawing a clear distinction between trafficking and smuggling, yet in doing so it adds to existing discussions by drawing attention to the role of exploitation in relation to both trafficking and smuggling (Section 2). In addition, the paper offers illustrative empirical evidence of the key building blocks of smuggling, namely the search for reliable information and the reaching of an agreement in regard to the service offered (Section 3). Furthermore, it discusses three different scenarios that may emerge from the interplay between smugglers and smuggled persons, and it specifies the role of exploitation in each scenario - thereby going beyond the received wisdom. The paper also pinpoints the juncture at which smuggling turns into trafficking (Section 4). Finally, Section 5 concludes by spelling out relevant policy implications.

\section{The distinctive features of trafficking and smuggling}

The 2000 UN Protocols as well as the earlier Europol Convention (1995) posit a clear distinction between trafficking and smuggling activities. This distinction is based on a set of constitutive features that separates the two phenomena. Table 1 summarises these:

Table 1. Distinctive features of smuggling and trafficking

[TABLE 1 HERE] 
In the case of smuggling, the commodity at stake is the illegal entry into a country, and it is exchanged between a smuggler and a prospective smuggled individual. In the case of trafficking, the commodity at stake is control over a human being. In some instances this commodity is exchanged between a trafficker and a third party, e.g. the family of the victim; in other cases it is acquired by traffickers by means of abduction or near-abduction (i.e. gross deception). If a trafficking operation is transnational, it may then involve the crossing of one or more borders illegally. However, illegal entry into a country is not a constitutive element of trafficking but rather an ancillary one. It is the unlawful right to exert control over a person that is exchanged in the first place, not the illegal crossing of a border. A person can be trafficked and yet enter a country legally. Moreover, trafficking can take place within the borders of a given country (internal trafficking). The type of offence involved also differs between smuggling and trafficking. The former is primarily an offence against the state. When everything goes well between smuggler and smuggled person, the only victim is the state - its borders have been violated as well as its right to exercise control over a given territory. Trafficking, on the other hand, is primarily an offence against a person. A state may see its sovereignty as being violated but the primary victim remains the person who was deprived of his/her freedom and rights. Finally, smuggling and trafficking differ in regard to the level of agency of the migrant. In the case of smuggling, the migrant has agency: he/she can collect information and make a choice, most crucially about which smuggling organisation is the best to pick in order to achieve the desired outcome, given the amount of money he/she is willing/able to pay. The choice may be between unattractive alternatives, but it is still a choice. In the case of trafficking, agency is non-existent by definition: either a third party sells the victim to the traffickers or the victim starts off making a choice and then his/her freedom is taken away. This does not contradict the dichotomy but rather supports it, since it makes apparent the possibility of a transition between two distinct 
states: that of smuggled person with agency and that of trafficked person without agency (see Scenario \#3 below).

Transitions from smuggling to trafficking may, then, take place. However, it is only if the two concepts are considered distinct that one can speak of there being such a transition and once can detect elements of one phenomenon in the other. For instance, journeys may start out as a smuggling operation and then turn into trafficking; things can turn sour during the course of the smuggling and the migrant may find himself/herself held in captivity.

There is an additional dimension to the smuggling vs. trafficking dichotomy that is often overlooked: namely the distinctive relationship that each phenomenon possesses with exploitation (for notable exceptions, see Munro 2008 and Wilkinson 2003). There are two broad understandings of the term exploitation. The first interprets exploitation as "wrongful use": namely a person is "being used solely as a means," and so he/she is "objectified and instrumentalised inappropriately" (Munro 2008: 84-85; see also Wilkinson 2003). The second view, broadly based on the Marxian tradition, interprets exploitation in terms of "disparity of value": that is, the person is "unfairly used, with this unfairness typically consisting in the fact that her position of vulnerability is taken advantage of in order to under-reward her role within a given transaction" (Munro 2008: 85; emphasis in the original). The first approach needs to specify the harm that is done to a person used solely as a means (clearly, using somebody as a means need not be exploitative). However, the domain of exploitation would thus expand to include almost any "bad" resulting from human activities. This paper adopts a definition that is more in line with the second approach; however, it qualifies this definition by situating it within the work place (otherwise any form of cheating would qualify as exploitation). In a nutshell, this paper will take exploitation to mean the act of treating someone with substantial unfairness in order to benefit for their work - a rendering that closely 
resembles the definition given by the Oxford Dictionary ${ }^{3}$. A well-developed set of labour laws defines what counts as "substantially unfair", such as paying people less than the minimum wage, failing to provide appropriate working conditions and regular holidays, and various forms of workrelated severe mistreatment.

Trafficking and exploitation are inextricably linked: victims of trafficking are forced into exploitative working conditions by the traffickers themselves or their associates. However, to turn this around, exploitation alone does not imply the presence of trafficking. This conceptual misunderstanding often leads to confusion on the part of commentators and policy-makers, and may lead to misconceived policies.

While trafficking and exploitation always go hand in hand, the relationship between smuggling and exploitation is less straightforward. Migrants may enter a country thanks to the services of a smuggling organisation and then find low-quality employment characterised by some degree of exploitation. Migrants may end up working longer hours than the locals or being employed in working environments with worse conditions. Exploitation of this kind is a consequence of the migrants' undocumented status, which makes them more likely to be employed in the informal economy where workers' rights are not protected by the state. In this case, exploitation takes place after the (successful) completion of the smuggling operation, and such an exploitative state of affairs is orthogonal to the smuggling agreement. In other instances, migrants may face an imbalance between their resources and aspirations, and find themselves in a situation where they have to borrow money for the journey. As a consequence, they may have to accept exploitative conditions in their workplace to pay back the debt accrued. Although on the face of it exploitation may be seen as a direct consequence of smuggling, it is in fact a constitutive element of the debt situation, and not of smuggling (see Scenario 2 below). In conclusion, a smuggled person may still retain the option of exiting a specific exploitative working "contract". At the same time, they may 
only have at their disposal options that are equally exploitative. The observed outcome would then invariably be some degree of exploitation. However, it is crucial to understand how exploitation was generated in that specific instance - as a result of a choice that was made by the migrant. Only a proper understanding of exploitation can help policy-makers develop better targeted strategies to eradicate it.

\section{Smuggling in practice: searching for reliable information}

The relationship between smugglers and migrants poses a series of theoretical problems. These result from a number of asymmetries between the actors involved. Firstly, smuggler and smuggled have an information asymmetry, with the latter usually being in a weaker position than the former, as in many market transactions (see, for example, Akerlof 1970). In addition, any transaction between the two actors takes place in an illegal market where information collection and verification are difficult, and where there are few mechanisms to enforce contracts and make sure people do not cheat or renege on their promises (Varese 2010; Campana and Varese 2013). Nevertheless, while there are no legal devices, both smugglers and smuggled can turn to some informal strategies. First, both parties collect reliable information on each other and their services. This follows from the assumption that smuggling involves a voluntary exchange (albeit one that might lead to exploitation).

A typical smuggling situation is characterised by an agreement between two parties, i.e. the smuggler and the smuggled person. Let us assume for simplicity a situation in which (a) the agreement is made before the start of the journey and is not re-negotiated throughout, and (b) the smuggler is a single actor (if migrants have to negotiate each leg of the journey separately, then this situation is repeated multiple times). The smuggler wants to be sure that the migrant is not a police informant and will not report him to the authorities, or that he/she does not belong to a competitor's 
"firm". Also, the smuggler wants to be sure that the migrant will pay the agreed fee for the service upon reaching the destination country. The migrant wants to be sure that the smuggler is a genuine smuggler and not, for example, a trafficker. In other words, the migrant wants to be sure that he/she will get the service the smuggler has promised and with the level of quality agreed (e.g. a safe passage, no violence involved, and no risk of being forced into unwanted employment). The search for information is an underexplored yet key element of the smuggling agreement and migrants actively engage in this search, as the instance detailed below exemplifies.

Anna is a Moldovan citizen who decided to purchase illegal entry into Italy from a smuggling organisation. ${ }^{4}$ When we interviewed her some five years after the journey, she was working as domestic help in northern Italy, with a regular contract and a permit to stay in the country.

When I decided to come to Italy I was already married. My husband and my family started to collect information on how to reach Italy illegally. A friend of my husband knew a person who worked as a chauffeur for a policeman. This person gave us the phone number of a lady and I got in contact with her. It is possible that this lady was married to a policeman or had some relatives in the police. Once we got the contact, my mother started to collect information from people who had already entered Italy in this way and thanks to this group. It looked like all the women reached Italy for real and without any problems. You hear stories of women who never made it to Italy and you can never trust these people [the smugglers]. But this lady looked reliable, and we got her contact from a guy who worked for the police. So I decided to trust them (Interview 1).

In the case of Anna, the police indirectly offered a guarantee as to the quality of the smuggling services and Anna's strategy was based on a simple assumption: the police are best placed to check 
the credentials of smugglers. In addition, Anna and her family actively collected information about the reputation of this specific group from among their acquaintances. Often multiple organisations offer smuggling services in a given area, and migrants make a choice based on the type of service offered, the quality and the price.

I had heard stories of other women that had relied on other methods, for instance crossing the border on foot or hidden underneath a car: the price for the journey is much cheaper when you use these other methods. However, I said that "I would prefer paying more but being safe; tell me how much it costs and I will pay" (Interview 1).

Mutual acquaintances, and their reputation, seem to play a role also among migrants from Africa. As described by Triandafyllidou and Maroukis (2012: 110), smugglers and migrants are often introduced by an acquaintance who also vouches for the good reputation of the smuggler. A meeting at the house of the migrant (i.e. the prospective customer) is then set up to discuss the terms of the agreement. Collecting information in the source country may be relatively easier than in transit countries, while negotiating each leg of the journey separately exacerbates the information problem, thus making migrants more vulnerable. For example, making a decision about competing smuggling organisations may be easier to do in Moldova for a Moldovan migrant that, say, in a Libyan harbour city for a Sudanese migrant.

Migrants collect information about what is on offer and make decisions based on the best available knowledge, taking into account personal and economic factors. They also voluntarily enter into transactions with smugglers. This does not rule out the possibility that they may have been pushed to migrate because of poverty, unemployment or family reasons; also, it does not say anything about the quality of the options a migrant may have at their disposal. 


\section{The making and breaking of informal agreements}

The making and breaking of agreements is a key element in smuggling. Smuggling is a situation in which the smuggler may or may not abide by the agreement; and the migrant may or may not be exploited. Exploitation may occur regardless of whether the agreement is honoured or not. If one leaves aside situations in which it is the migrant who does not hold to the agreement, there are four possible scenarios, as outlined in Table 2 . We consider here only non-trivial breaches of the agreement that may take place once the smuggling process is already under way (this rules out instances of pure cheating that may happen before the process starts). In Scenario 1, the smuggler abides by the agreement and the migrant is not exploited. In Scenario 2, the smuggler abides by the agreement and the migrant is exploited. In Scenario 3, the smuggler does not abide by the agreement and the migrant is exploited. One could also think of a fourth possibility, namely when the smuggler does not keep to the agreement with the migrant and the latter is not exploited. However, in situations in which the breach of the agreement is non-trivial, this scenario is unrealistic as every breach of the agreement is likely to bring to exploitation. For this reason, we shall not discuss the fourth scenario at length, but focus only on the first three scenarios.

Table 2: The interplay between keeping promise and exploitation

Below the paper discusses in more detail scenarios 1, 2 and 3 and presents relevant evidence in each case.

\subsection{Scenario \#1: agreement is honoured and there is no exploitation}


In the first scenario, the smuggler respects the agreement and the migrant is safely transported to the destination country with no harm or exploitation. Both the smuggler and the migrant are better off and the only victim is the state that has its borders violated. The case of Anna mentioned above is an example of this scenario. Anna was smuggled from Chisinau (Moldova) to Padua (Italy) in November 2007. The journey started on a Friday and lasted until Sunday. Anna was first driven to Odessa where she boarded a train to Chop (Ukraine). The smuggling group bought her ticket and gave her a mobile phone to keep in contact with them and to obtain assistance in the case of unforeseen events. The organisation also provided her with a script to be used with the border police as well as $€ 500$ to buy additional tickets and bribe corrupt officials, if needed. At Chop, she crossed the border into Hungary and boarded another train to Budapest. There she was picked up by a member of the organisation and driven to a hotel some 25 kilometres outside the city, where she spent the night. The smugglers based in Budapest originated from the same city as Anna. The following morning she was given a fake Romanian passport and a new script to memorise, and drove first into Austria and then Italy. She reached Padua at 2am on Sunday (Interview 1).

These are the terms of the agreement with the smugglers in Anna's own words:

They never promised me work in Italy. The agreement was clear: I would receive only a journey to a destination of my choice in Italy. This destination would have been within a given range from the border with Austria, say Padua, Venice, or maybe somewhere else in the northeast of Italy. I bought only a passage into Italy from them [the smugglers] (Interview 1).

This scenario covers cases that are successful for both smugglers and the smuggled individual, and thus this scenario is more likely to go undetected. No exploitation is present. 


\subsection{Scenario \#2: agreement is honoured, but exploitation is present}

In the second scenario, the smuggler holds to the agreement but the migrant ends up being exploited in the destination country. However, such exploitation is a direct consequence of the migrant's status as an undocumented migrant, rather than as a result of smuggling per se. It is possible that the agreed price for the smuggling services is disproportionally higher than the money the migrants has at his or her disposal before starting the journey. This is more likely to happen in the case of a long journey (e.g. from China to Europe) and/or from a country with a weak currency (smuggling services are often priced in hard currency such as Euros or US dollars). Thus, the migrant may be cheated into paying a higher fee than the best "market price", but this does not imply work-related exploitation.

Examples of cases of Scenario \#2 are the stories of Bangladeshi workers documented by Triandafyllidou and Maroukis (2012: 153-154). These workers, based in Greece, entered the country as undocumented migrants and found work in agriculture. They would earn some $€ 22$ per day, live in makeshift huts and put in very long hours. However, the exploitation they experienced is not a direct consequence of the smugglers' actions. These migrants are exploited in the workplace, as vividly recounted by Bangladeshi workers:

I went to Athens and stayed there for one month. After that, I tried to live in Greece legally but I couldn't. It was a big problem! So I decided to come here to the village [in the Peloponnese]. I've been here eight months. It is very difficult! One month we're working, one month we aren't working. From what I heard things were different in the past (quoted in Triandafyllidou and Maroukis 2012: 154). 
Arguably, the following story of Yan, a 31-year old woman from Wenzhou, China, whom we interviewed in northern Italy, is also an example of Scenario \#2. ${ }^{5}$ Yan works in a massage parlour. Her daily shift starts around 10am and ends at midnight; she is entitled to some days off but not on a regular basis. We could not quantify the length of her annual leave, but she told us that she spends a month in China every three years and occasionally has some days off with her sister, who lives in a nearby region. The cost of the journey was around $€ 15,000$, and it was arranged by a Chinese national based in Italy. This person was chosen by Yan's sister, who had moved to Italy five years earlier. The sum of $€ 15,000$ was paid by Yan's sister. At the time of the interview, Yan had been in Italy for more than three years and had returned to China once. The airfare for the round-trip to China was around $€ 2,000$, which was lent to Yan by her sister. Yan said that in three years she had managed to pay back her sister some $€ 11,000$ and that $€ 6,000$ remained outstanding. Yan lives in accommodation at a driving distance from the parlour. She maintains that she has her passport with her. She is connected to the Internet via her smartphone and laptop. She maintains that she has freedom of physical movement as well as freedom to access the Internet. She also showed us a Skype account with a list of names of Italian citizens with whom she claims to have had conversations (Interview 2).

Clearly, Yan was working under exploitative conditions (these conditions would also be defined as exploitative under Italian law), as she was putting in 14-hour shifts, with no regular days off and no statutory protection. In addition, she had to pay back a large debt to her sister (and not to the smuggler). The case of Yan falls into the labour-exploitation category, but there are no grounds to classify her case as one of trafficking. The smuggling organisation appears to have held to the agreement. Based on her account, given to us in strict confidence, Yan was able to pay back some $€ 300$ per month to her sister, which translates into some 19 more months of payments. ${ }^{6}$ We do not know whether she will be looking for a different job after she has paid back the entire sum. 
In this scenario, the smuggled person buys two different goods at the same time: (a) entry into a country for price $\mathrm{X}$ and (b) a loan often equal to $\mathrm{X}$. Both goods are then delivered according to the agreements in place. The loan may have highly unfavourable conditions attached to it in a direct or indirect way, while exploitative working conditions can be limited to a certain period of time and then ended according to the agreement. It is often the case that illegal migrants earn significantly less than nationals. The Chinese migrants studied by Silverstone (2011: 106) were receiving less than the minimum wage: in the catering sector the estimated wage was between $£ 3.33$ and $£ 4.16$ per hour. In this scenario, a migrant finds herself working under exploitative conditions despite all the agreements being respected. Sometimes a degree of labour exploitation is already factored in to the decision to leave the home country. Silverstone (2011: 100) found that, in the case of Chinese migration, most migrants "had a fairly accurate idea of what they were facing on arrival in the United Kingdom. Those who had a view had a reasonably realistic grasp of the wages on offer and the kind of employment opportunities available". This was also the case for sex workers (Silverstone 2011: 108). However, these cases do not imply that deceptive practices or force are used.

\subsection{Scenario \#3: the agreement is not honoured and exploitation is present}

In the third scenario, the smuggler does not respect the agreement and the migrant is exploited as a direct consequence. Exploitation can happen in a variety of ways, including as a result of coercion or deception. In this scenario, the migrant may still have some exit options, but the cost of choosing them might be too high (e.g. the prospect of long-term imprisonment followed by extradition). In other cases, he or she may not have any option at all - a situation that closely resembles a kidnapping. The journey may have started with the full consent of the migrant but subsequently 
turned into a trafficking operation in which the migrant is forced to work and/or is kept in a place against their will. From the point of view of the migrant, this is a failure of smuggling. For one thing, the information collected by the migrant before the trip proved unreliable. On the other hand, the outcome is what the trafficker wanted from the beginning: he deceived his victim. To put it in other words, for the migrant Scenario \#3 represents a transition from smuggling to trafficking.

Examples of Scenario \#3 are the so-called "Natasha stories" described by Hughes (2000) and Malarek (2003), who claim that such cases are widespread. ${ }^{7}$ The Taiwanese-born journalist and writer Hsiao-Hung Pai has published an exposé of "Britain's migrant sex workers" (2013). In order to conduct her research, she worked undercover as a brothel house keeper and cleaner. Among several cases of women genuinely smuggled from outside the EU and working in the sex industry, she came across one case that would fit the 'Natasha' model. Galina is a 21-year-old Lithuanian woman from a low-income family. At a Christmas party she met a girl called Wioleta, who eventually promised her a baby-sitting job in the UK. Galina paid $£ 400$ for the trip. On the way to the UK, Galina and Wioleta stopped in Albania, where it transpired that Galina had been sold into prostitution. There she was raped. When Galina arrived in London three weeks later, she was taken to live with two Albanian men who forced her to work in a massage parlour in central London. Apparently the owner of the establishment was not aware of Galina's condition. Over a period of several months, Galina was moved from London to other UK cities and forced to give up the money she earned. Eventually, a Russian customer befriended her and she told him about her condition of imprisonment and isolation. The customer was shocked and quickly reported the case to the police (Pai 2013: 276-287).

\subsection{Strategies to support agreements between smugglers and migrants}


Although smuggling takes place in the informal economy, devices do still exist to increase the likelihood that a smuggler will not breach their agreements (Campana and Varese 2013). These include the possibility of not paying the entire sum up front but making it conditional on the safe arrival of the smuggled person at the final destination. A third party may act as a guarantor and may witness the arrival into the destination country. In the case of Anna, the money was actually paid to the smuggling group only upon her safe arrival in Italy, while her brother - who was already living in Italy - acted as guarantor:

Once I reached Padua, I called my brother and asked him to come to a car park and pick me up. My brother came and they [the smugglers] asked me how much of the $€ 500 \mathrm{I}$ had received from them was left. I said $€ 100$, and handed it back. They also asked for the fake Romanian passport and the mobile phone. Once my brother arrived, we made a phone call to the lady back in Moldova and at that very moment my mother paid the $€ 4,150$ we had agreed for the journey. The two [smugglers] then left the car park, saying 'we have never seen each other before, right?' (Interview 1).

In all of the cases of migration from Southeast Asia analysed by Triandafyllidou and Maroukis (2012) a guarantor was involved. ${ }^{8}$ Guarantors do not always belong to the migrant's family. In some instances, this role is performed by a "professional" who acts as an informal bank: he receives the money from the migrant before the start of the journey and does not release it to the smuggler until the migrant has safely reached his or her destination (Triandafyllidou and Maroukis 2012: 134). The system works based on a code: when receiving the money, the guarantor gives a code to the migrant, and it is this code - known only to the migrant - that will eventually unlock the money once he or she has reached the destination country. The guarantor charges a service fee, which is usually around 3 per cent of the sum deposited (Triandafyllidou and Maroukis 2012: 134). 
Reputation is a key asset for guarantors: they often own a business in the place of origin of the migrant (or more generally in the place where the journey starts) and have "a recognizable role in the local community so that both the smuggling broker and the migrant's family trust him" (Triandafyllidou and Maroukis 2012: 134). In addition, they tend to run businesses that are easy to locate and difficult to move, such as corner shops and call centres. This should increase the assurance for both smugglers and migrants that guarantors will not flee overnight (although there have also been instances in which guarantors did just disappear with the cash: Triandafyllidou and Maroukis 2012: 169). When cooperation between smugglers and migrants breaks down, the former may resort to hostage-taking strategies, such as keeping migrants in safe houses until the debt is paid off. Triandafyllidou and Maroukis (2012: 127 and 140) documented instances of Asian migrants being kept in safe houses in Turkey en route to Europe due to problems with payments.

\section{Conclusions}

How we define human trafficking, and particularly the extent of the domain that term is deemed to cover, matters. Maintaining a clear distinction between trafficking and smuggling has a continued significance, as it allows us to capture the essential features of the two phenomena, including the distinctive relationship that each possesses with exploitation. This paper has defended the distinction and has also discussed at some length three different scenarios that may emerge from the interplay between smugglers and smuggled persons. In so doing, it has specified the role of exploitation in each scenario. The paper has also highlighted the juncture at which smuggling turns into trafficking, and it has explored the search for reliable information that both parties may undertake before entering into a smuggling agreement. Both smugglers and migrants may adopt strategies to support such an agreement. 
The adoption of a very broad definition of trafficking, and the consequent blurring of the distinction between smuggling and trafficking, has a number of undesirable consequences. Victims of trafficking need adequate psychological support, shelter and assistance for prolonged periods, while migrants successfully smuggled into the country are more at risk of being exploited in the local economy. Traumatised trafficked people need different kinds of help to victims of on-the-job exploitation.

In addition, if we expand the category of trafficking by including under it instances of smuggling, we may end up limiting its scope by just focusing on the dyad of victim and perpetrator. In this way, we would leave out a crucial player - namely regulators - and possibly set off a course of events that would lead to ineffective policies. Instead, an emphasis on work-related exploitation an emphasis that this paper advocates - fully takes into consideration the actions of other actors, such as state regulators and legal yet unscrupulous employers. Ultimately, states (i.e. regulators) are not just bystanders whose only role is to "rescue" victims from the hands of traffickers: they are often key players, having the ability to set rules regarding requirements for entry into a country, working conditions and business practices, as well as having the power to grant legal status to a given industry. A focus on exploitation easily allows policy-makers to devise norms that protect victims, while maintaining the distinction that is already in place. For instance, a sex worker may be exploited - by being pressured to perform unsafe sex and work in unsanitary conditions and for long hours - without being a victim of trafficking. As documented at length by Pai (2008), exploitation is rife in the sex industry: working standards are low and women work very long shifts. Yet equating exploitation with trafficking is not only conceptually flawed, but may engender a moral panic (Cohen 1972/1980) that would be conducive to overly repressive strategies and penal populism (Roberts and Hough 2002; Roberts 2003). In addition, labour exploitation extends beyond the sex industry, and may be particularly acute in sectors like agriculture, manufacturing, construction or domestic work (see, for example, Pai 2008). 
When it comes to smuggling, there is an additional - yet unavoidable - trade-off in any policy that attempts to address undocumented migration. As it has been argued above, trafficking and smuggling involve two distinct types of offence. The first is primarily an offence against a person, while the latter is primarily an offence against a state. It therefore follows that two different sets of policies have been developed: (a) individual-oriented policies; and (b) state-oriented policies. Individual-oriented policies are those aimed at protecting the welfare of a victim of human trafficking and/or exploitative working conditions. State-oriented policies are those aimed at protecting the right of a state in regard to its territory, including control of the movement of people across its borders. These policies have different purposes, and these purposes might often be in contradiction with each other (see also Bosworth 2008 and Duvell 2014). For instance, stateoriented policies can aim to reduce the size of smuggling, e.g. through a harsh crackdown on smugglers. As a consequence, this could destabilise the market and create a much more turbulent environment. Smugglers may react by shortening their time-horizon, which in turn will increase their incentives to renege on their agreements. The number of broken agreements may thus increase, and with this increase would come a concomitant rise in the harming of migrants. A policy that protects the welfare of smuggled persons should promote smooth transactions between smugglers and smuggled individuals. If things turn sour for the smuggled person, the policy should protect their rights - no matter if they have infringed some regulations - thus putting the reduction of harm to migrants first. This can, however, lead to undesirable consequences for states: if the journey is smooth and safe for both sides, more people will embark on it and the number of illegal entries will increase. Secondly, more smugglers may enter the market, increasing the supply of smuggling services and perhaps decreasing the price charged for them. While it is ultimately for policy-makers to decide the appropriate mix of individual-oriented and state-oriented policies, this paper advocates in the first instance a greater awareness of this trade-off. 
The EU recently attempted to introduce measures aimed at tackling the demand for trafficking across its Member States (Directive 2011/36/EU). According to this EU Directive, states should criminalise the use of services that are the object of trafficking-related exploitation (Article 18(4)). In 2010, England and Wales started to criminalise the purchasing of services from sex workers who had been subject to trafficking and exploitation by putting into force a new strict liability offence that was introduced in 2009. Kingston and Thomas (2014) provide an assessment of this measure, and conclude that it is ineffective and potentially subject to abuse. Other countries have gone further and have decided to criminalise the purchasing of sexual services tout court. The first such country, in 1999, was Sweden (hence, the oft-used label the 'Swedish model': Gould 2001). Sweden has outlawed the purchasing of sexual services of any kind, but not their sale. However, the effectiveness of this abolitionist approach in tackling trafficking has been called into question, and the preliminary evidence from Sweden is far from being unambiguously positive due to displacement effects and adverse dynamics affecting the "survival" sex workers (Levy and Jakobsson 2014); in addition, the number of traffickers reported by the police has been rather stable in the last ten years with an average of 26 individuals/year and a rather low conviction rate of about 6 per cent (Dodillet and Östergren 2011: 13; Eurostat 2014: 114) ${ }^{9}$. Huschke et al. (2014) surveyed 171 sex workers as part of a study of prostitution in Northern Ireland. They found that 85 per cent of the interviewees believed that making it illegal to pay for sexual services would not reduce the level of trafficking (indeed, just 8 per cent believed it would: p. 181). According to some interviewees, this measure might even have the unintended consequence of increasing the risk and potential harm experienced by sex workers. Respondents feared that "decent" non-violent clients would be driven away from the market, and as a consequence sex workers would be forced to accept more violent clients. This, in turn, would increase the need for protection and thus the involvement of organised crime groups (Huschke et al. 2014: 178-180). 
Criminalising the consumers of sexual services may have an additional unintended consequence: it may increase the difficulties for the authorities in terms of identifying victims and building strong cases against offenders. This is because migrants who have been deceived into being trafficked constitute a hard-to-reach population. For example, if a trafficked woman is forced to work as a prostitute, her clients could be the only contact point between her and the "outside" world. A client would be more willing to report situations of extreme exploitation and trafficking to the authorities if: (a) he is confident that the authorities will treat the victim with fairness and will not impose punitive penalties on her; and (b) he will not be criminalised for his actions, nor morally stigmatised. Criminalising the purchasing of sex may, however, work in the opposite direction. For instance, the only case of trafficking in the sex industry mentioned in Pai (2013) was discovered thanks to a client voluntarily reporting it to the police. The role played by some customers in identifying victims of trafficking is also confirmed by a social worker we have interviewed:

Based on our own experience with assisting victims of trafficking, I reckon that 50 per cent of victims were rescued thanks to the assistance of former customers who decided to help these women, whereas the other 50 per cent of victims voluntarily reported their situation to the police. Criminalised customers will fear the penalties and also feel a strong sense of shame; as a reaction, prostitution will become ever more hidden. Instead of criminalising them, customers should be educated. (Interview 5)

In this paper it is only possible to touch upon the long-standing debate about the legalisation, and thus regulation, of sexual services. Nonetheless, it is worth noting that many of the issues arising in markets as diverse as prostitution, agriculture or catering mostly relate to labour exploitation rather than trafficking. A better strategy would be to adopt a set of policies to create better working 
conditions and prevent abuse and exploitation in the workplace, such as lowering the cost for undocumented workers of reporting inhumane working conditions. Therefore, migrants' rights and their living standards will in most cases be better protected and enhanced by focusing on regulation rather than repression or criminalisation (on this, see also Bosworth and Guild 2008; Aliverti 2012). Ultimately, this paper supports polices that focus on reducing exploitation in the workplace and increasing the welfare of workers through better regulations. 


\section{Funding:}

This work was supported by the European Union / FP7 Framework (Fiducia Project, Grant agreement 290563, FP7-SSH-2011-12).

\section{Acknowledgments}

The authors are listed in alphabetic order. We are grateful to three anonymous referees, the Editor and Michael Biggs for extremely helpful suggestions on how to improve the article. We are also grateful to audiences at the $14^{\text {th }}$ Annual Conference of the European Society of Criminology (Budapest, 4-7 September 2013) and the workshop 'Trafficking and Smuggling: A European Perspective' (Nuffield College Oxford, 2 December 2013). We also have a debt of gratitude to Giorgia Cigalla for carrying out the interviews in Bologna. 


\section{Bibliography}

\section{$\underline{\text { Interviews }}$}

Interview 1. Anna [fictitious name]: Piedmont, Italy, December 2012

Interview 2. Yan [fictitious name]: Piedmont, Italy, April 2012

Interview 3. Social worker, PIAM: Asti, Italy, February 2014

Interview 4. Social worker, Fiori di strada: Bologna, Italy, April 2014

Interview 5. Social worker, Casa delle donne: Bologna, Italy, April 2014

\section{$\underline{\text { Official documents }}$}

EU (2009). European Union Council Decision establishing the European Police Office (Europol). 2009/371/JHA.

EU (2011). Directive 2011/36/EU of the European Parliament and of the Council of 5 April 2011 on preventing and combating trafficking in human beings and protecting its victims.

Europol Convention (1995). Council Act of 26 July 1995 drawing up the Convention on the establishment of a European Police Office. 95/C 316/01.

UN (2000a). Protocol to prevent, suppress and punish trafficking in persons, especially women and children, supplementing the United Nations Convention against Transnational Organised Crime.

UN (2000b). Protocol against the smuggling of migrants by land, sea and air, supplementing the United Nations Convention against Transnational Organised Crime.

\section{$\underline{\text { Books and articles }}$}

Aliverti, A. (2012). Making people criminal: The role of the criminal law in immigration enforcement. Theoretical Criminology, 16(4), 417-434.

Agustín, L. M. (2005). Migrants in the mistress's house: Other voices in the "trafficking" debate. Social Politics: International Studies in Gender, State and Society, 12(1), 96-117.

Akerlof, G. (1970). The Market for Lemons: Quality Uncertainty and the Market Mechanism. Quarterly Journal of Economics 84: 488-500.

Annison, R. (2013). In the Dock. Examining the UK's Criminal Justice Response to Trafficking. London: The Anti-Trafficking Monitoring Group. 
Aronowitz, A. A. (2001). Smuggling and trafficking in human beings: the phenomenon, the markets that drive it and the organisations that promote it. European Journal on Criminal Policy and Research, 9(2), 163-195.

Bales, K. (2012). Disposable people: New slavery in the global economy. Oakland: University of California Press.

Bosworth, M. (2008). Border control and the limits of the sovereign state. Social \& Legal Studies, 17(2), 199-215.

Bosworth, M. and Guild, M. (2008). Governing Through Migration Control Security and Citizenship in Britain. British Journal of Criminology, 48(6), 703-719.

Bufacchi V. (2002). The Injustice of Exploitation. CRISPP 1:1-15.

Bunt, H van de. (2008). "The Role of Hawala Bankers in the Transfer of Proceeds from Organized Crime". In Dina Siegel and Hans Nelen (eds.), Organized Crime. Culture, Markets and Policies. New York: Springer, pp. 113-126.

Campana P. (2015). "The Structure of Human Trafficking: Lifting the Bonnet of a Nigerian Trafficking Network”. British Journal of Criminology, online first.

Campana P. and F. Varese (2013). Cooperation in Criminal Organizations: Kinship and Violence as Credible Commitments. Rationality and Society, 25(3), 263-289.

Caneppele, S. and M. Mancuso (2013). Are protection policies for human trafficking victims effective? An analysis of the Italian case. European Journal on Criminal Policy and Research, 19(3): 259-273.

Chin, K-L and J.O. Finckenauer. (2012). Selling Sex Overseas. Chinese Women and the Realities of Prostitution and Global Sex Trafficking. New York, NY: New York University Press.

Cohen, S. (1972/1980). Folk Devils and Moral Panics: The Creation of the Mods and the Rockers. Oxford: Basil Blackwell.

Danailova-Trainor, G. and F. Laczko (2010). Trafficking in persons and development: towards greater policy coherence. International Migration, 48(4), 38-83.

Dodillet, S. and P. Östergren, (2011). "The Swedish sex purchase act: Claimed success and documented effects". Conference paper presented at the International Workshop:

Decriminalizing Prostitution and Beyond: Practical Experiences and Challenges. The Hague, March 3-4.

Duvel F. (2014). Human trafficking, border deaths and the migration apparatus. Book review. Migration Studies, 2(3), 448-454.

Eurojust (2012). Eurojust's action against trafficking in human beings. Final report. The Hague: Eurojust. 
Eurostat (2014), Trafficking in human beings. Luxembourg: European Union.

Gallagher A.T. (2009). Human Rights and Human Trafficking: Quagmire or Firm Ground? A Response to James Hathaway. Virginian Journal of International Law 50(1): 789-848.

Gould, A. (2001). The criminalisation of buying sex: The politics of prostitution in Sweden. Journal of Social Policy 30(03): 437-456.

Gozdziak, E. M. and E. A. Collett (2005). Research on human trafficking in North America: A review of literature. International Migration, 43(1-2), 99-128.

Hathaway, James C. (2008). The Human Rights Quagmire of 'Human Trafficking'. Virginia Journal of International Law, 49(1): 1-59.

Hales, L. and L. Gelsthorpe (2012). The Criminalisation of Migrant Women. Cambridge: Institute of Criminology.

Hoyle C., M. Bosworth and M. Dempsey (2011). Labelling the Victims of Sex Trafficking: Exploring the Borderland between Rhetoric and Reality. Social \& Legal Studies 20: 313-329.

Hughes, D. M. (2000). The" Natasha" trade: The transnational shadow market of trafficking in women. Journal of International Affairs, 53(2), 625-652.

International Organization for Migration (2006). Human Trafficking Survey: Belarus, Bulgaria, Moldova, Romania, and Ukraine. Kyiv: International Organization for Migration.

Kara, S. (2009). Sex trafficking: Inside the business of modern slavery. New York: Columbia University Press.

Kleemans, E. (2011). Human smuggling and human trafficking. In M. Tonry (ed.), Oxford Handbook on Crime and Public Policy, Oxford: Oxford University Press, pp. 409-427

Kleemans E. and H. van de Bunt (2003). The Social Organisation of Human Trafficking. In D. Siegel, H. van de Bunt and D. Zaitch (eds.). Global Organized Crime. Dordrecht: Springer Netherlands, pp. 97-104.

Kingston, S. and T. Thomas (2014). The Police, Sex Work, and Section 14 of the Policing and Crime Act 2009, The Howard Journal of Criminal Justice 53:3, 255-269.

Levy, J. and P. Jakobsson (2014). Sweden's abolitionist discourse and law: Effects on the dynamics of Swedish sex work and on the lives of Sweden's sex workers, Criminology and Criminal Justice, online first.

Malarek, V. (2003). The Natashas: Inside the New Global Sex Trade. New York: Arcade Publishing. 
Mai N. (2010). Migrant Workers in the UK Sex Industry. Final Report. Institute for the Study of European Transformation. London Metropolitan University.

Mancuso, M. (2013). Not all madams have a central role: analysis of a Nigerian sex trafficking network. Trends in Organized Crime 17: 66-88.

Munro V. E. (2008). Exploring Exploitation: Trafficking in Sex, Work and Sex Work. In Munro V. and della Giusta, Marina (eds), Demanding Sex: Critical Reflections on the Regulation of Prostitution. Abingdon, Oxon: Ashgate.

Pai, H.H. (2008). Chinese Whispers. The True Story behind Britain's Hidden Army of Labour. London: Penguin Books.

Pai, H.H. (2013). Invisible: Britain's Migrant Sex Workers. London: The Westbourne Press.

Roberts J. (2003). Penal populism and public opinion: Lessons from five countries. Oxford: Oxford University Press.

Roberts, J. and M. Hough (2002). Changing Attitudes to Punishment. Portland, Or.: Willan Publishing.

Salt, J. (2000). Trafficking and human smuggling: A European perspective. International Migration 38(3): 31-56.

Salt, J. and Stein, J. (1997). Migration as a business: the case of trafficking. International migration, 35(4), 467-494.

Savona E.U., A. Di Nicola and S. Decarli (2002). Mon-Eu-Traf: A Pilot Study on the Three European Union Key Immigration Points for Monitoring the Trafficking of Human Beings for the Purpose of Sexual Exploitation across European Union. Milan: Trento: Transcrime Reports.

Savona E.U., R. Belli, F. Curtol, S. Decarli and A. Di Nicola (2003). Trafficking in Persons and Smuggling of Migrants into Italy. Milan / Trento: Transcrime Reports.

Savona, E. U. and S. Stefanizzi (eds.) (2007). Measuring human trafficking. New York: Springer.

Silverstone, D. (2011). From Triads to snakeheads: organised crime and illegal migration within Britain's Chinese community. Global Crime, 12(2), 93-111.

Shelley, L. (2010). Human Trafficking: A Global Perspective. Cambridge, UK: Cambridge University Press.

Spencer, J. and R. Broad (2012). The 'Groundhog Day' of the Human Trafficking for Sexual Exploitation Debate: New Directions in Criminological Understanding. European Journal on Criminal Policy and Research, 18(3), 269-281.

Triandafyllidou, A. and T. Maroukis (2012). Migrant Smuggling: Irregular Migration from Asia and Africa to Europe. Basingstoke: Palgrave Macmillan. 
Varese, F. (2010). What is Organized Crime? Introduction to F. Varese (ed.), Organized Crime, Routledge, pp. 1-35.

Weitzer, R. (2007). The Social Construction of Sex Trafficking: Ideology and Institutionalization of a Moral Crusade. Politics \& Society 35(3): 447-75.

Weitzer, R. (2005). Flawed Theory and Method in Studies of Prostitution. Violence Against Women 11(7): 934-49.

Wertheimer, A and M. Zwolinski (2013). Exploitation. In E.N. Zalta (ed.), The Stanford Encyclopedia of Philosophy, http://plato.stanford.edu/archives/spr2013/entries/exploitation/

Wheaton, E. M., E. J. Schauer and T. V. Galli (2010). Economics of human trafficking. International Migration, 48(4): 114-141.

Williams, P. (ed.) (2012). Illegal immigration and commercial sex: The new slave trade. London: Routledge.

Wilkinson S. (2003). Bodies for Sale: Ethics and Exploitation in the Human Body Trade. London: Routledge.

Zhang, S.X. (2009). Beyond the 'Natasha' story - a review and critique of current research on sex trafficking, Global Crime 10(3): 178-195.

Zhang, S.X. (2008). Chinese Human Smuggling Organizations - Families, Social Networks, and Cultural Imperatives Stanford: Stanford University Press. 
TABLES

Table 1. Distinctive features of Smuggling and Trafficking

\begin{tabular}{|l|l|l|}
\hline Features & Smuggling & Trafficking \\
\hline Commodity: & Illegal entry into a country & Control over an individual \\
\hline $\begin{array}{l}\text { Actors involved in the } \\
\text { exchange: }\end{array}$ & $\begin{array}{l}\text { Smuggled person and } \\
\text { smuggler(s) }\end{array}$ & Third party and trafficker(s)* \\
\hline Offence against: & State's immigration laws & Person \\
\hline $\begin{array}{l}\text { Level of agency of the } \\
\text { smuggled person: }\end{array}$ & High & Absent or nearly absent \\
\hline
\end{tabular}

Note: $(*)$ With the exception of situations where abduction or near-abduction is employed.

Table 2. The interplay between keeping a promise and exploitation

Migrant is not exploited Migrant is exploited

Smuggler keeps promise

Smuggler does not keep

promise

\begin{tabular}{|c|c|}
\hline Scenario 1 & Scenario 2 \\
\hline$[$ Scenario 4] & Scenario 3 \\
& \\
\hline
\end{tabular}




\section{ENDNOTES:}

${ }^{1}$ The need to draw a line between trafficking and smuggling operations had already emerged by the early 1990s during the preparatory work for the setting up of Europol, the European Police Office, and it is reflected in the Convention adopted in 1995 (Europol Convention 1995). In this document, smuggling and trafficking are treated as distinct phenomena.

${ }^{2}$ The UN definition of trafficking was also adopted by the Council of Europe in their Convention on Action against Trafficking in Human Beings and then included in the EU Directive on Preventing and Combating Trafficking in Human Beings. ${ }^{2}$ Europol's mandate was also changed by the EU Council Decision of 6 April 2009 (2009/371/JHA) to reflect a broader definition of exploitation that now includes all the cases referred to in the UN Protocol as well as child pornography.

${ }^{3}$ See: http://www.oed.com/

${ }^{4}$ Anna is a fictitious name.

${ }^{5}$ Yan is a fictitious name.

${ }^{6}$ The story of Yan is consistent with the findings of Silverstone (2011: 103) in his survey of Britain's Chinese community. In his sample, the fees ranged from $£ 8,500$ to $£ 24,000$, with the mean fee being $£ 15,800$.

${ }^{7}$ Other cases are documented by Hales and Gelsthorpe (2012).

${ }^{8}$ Similarly, Bunt (2008: 121) reports the case of an Iraqi national living in the Netherlands engaged in money transfers who acted as an informal notary in cases of human smuggling. He (rather than the smugglers) would receive the payments for a smuggling operation and would release the money to the smugglers only after the person had safely reached his or her destination.

${ }^{9}$ The year 2006 appears to be an outlier, with a conviction rate of 42 per cent (11 individuals), and therefore was excluded from the calculation (when included, the average is 11 per cent). 